\title{
Effect of Diamine in Amine-Functionalized MIL-101 for Knoevenagel Condensation
}

\author{
Palraj Kasinathan, ${ }^{\dagger \neq}$ You-Kyong Seo, ${ }^{\dagger}$ Kyu-Eun Shim, ${ }^{\dagger \neq}$ Young Kyu Hwang, ${ }^{\dagger, *}$ U-Hwang Lee, ${ }^{\dagger, *}$ Dong Won Hwang, ${ }^{\dagger}$ \\ Do-Young Hong, ${ }^{\dagger}$ Shiva B. Halligudi, ${ }^{\dagger}$ and Jong-San Chang ${ }^{\dagger, \ddagger}$ \\ ${ }^{\dagger}$ Research Group for Nanocatalyst, Korea Research Institute of Chemical Technology, Daejeon 305-600, Korea \\ *E-mail: ykhwang@krict.re.kr(Y.K.H); uhwang@krict.re.kr(U-H.L) \\ \$School of Science, University of Science and Technology (UST), Daejeon, 305-333, Korea \\ Received February 28, 2011, Accepted April 6, 2011
}

Key Words : MOF, MIL-101, Pore size, Coordinatively unsaturated metal sites (CUS), Knoevenagel condensation

Crystalline Metal-Organic Frameworks (MOFs) are currently an important kind of advanced functional materials due to their novel coordination structures, diverse topologies, and potential applications. ${ }^{1-5}$ As one of topical MOFs, porous chromium terephthalate with giant pores labeled MIL$101(\mathrm{Cr})$ possesses several unique features such as hierarchical pore structure ${ }^{6}$ including a mesoporous zeotype architecture, mesoporous cages and microporous windows, outstanding sorption properties, numerous unsaturated metal cation sites, and high hydrothermal and chemical stability. These properties have led to a number of application potential in catalysis, gas storage, drug delivery and adsorptive separation. $^{7-10}$ One important challenge has to realize is funtionalization via incorporation of binding site or reactive centers for catalysis. The functionalization methods of metal organic frameworks (MOFs) in a wide range of applications are two possible approaches including pre- and postmodification with functional groups. ${ }^{7,9-15}$

The functionalized pores of MOFs can be used as active sites in base-catalyzed reactions. ${ }^{13,16-19}$ It was already described on an electrophilic surface functionalization of coordinatively unsaturated metal sites (CUS) with chelating agents or electron-rich molecules. MIL-101(Cr) may thus be finely tuned for catalytic applications in precise conditions. It is known that MIL-101(Cr) possesses two coordinatively unsaturated metal sites (CUS) in a trimeric Cr(III) octahedral cluster (Scheme 1) with terminal water molecules which are removable from the framework under vacuum or in an inert gas flow at $423 \mathrm{~K}$ for $12 \mathrm{~h}$. This CUS as Lewis acid sites in the structure was usable for the surface functionalization ${ }^{7}$ (Figure 1).

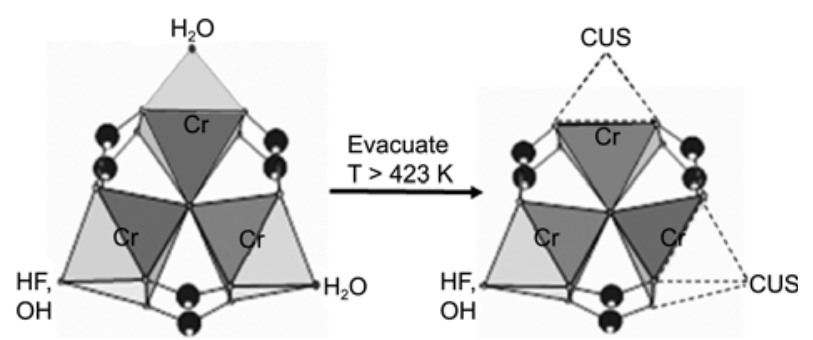

Scheme 1. Evolution of coordinatively unsaturated $\mathrm{Cr}(\mathrm{III})$ sites from chromium trimer after vacuum treatment $423 \mathrm{~K}$ for $12 \mathrm{~h}$.
Here we further explore the preparation of the aminegrafted MIL-101 as a heterogeneous base catalyst according to a $\mathrm{p} K_{\mathrm{a}}$ value of the functional diamine group and their catalytic activities in Knoevenagel condensation of benzaldehyde and ethylcynoacetate. The diamine compounds used for the functionalization include ethane-1,2-diamine (ED), butane-1,4-diamine (BD), decane-1,10-diamine (DD) and benzene-1,4-diamine (PD).

The XRD patterns of functionalized samples show decrease of intensity. These results provide that the diamines were filled the pores of MIL-101. However, the patterns still show the high-crystalline frameworks and porous structures after functionalization. (Supplementary Materials, Figure S1) The structural details of the pores such as BET surface area, pore volume and pore size are exhibited in Supplementary Materials (Figure S2 and Table S1). Figure 1 shows the $\mathrm{N}_{2}$ adsorption isotherms of as-prepared and functionalized MIL-101. The as-prepared MIL-101 has BET surface area of $4035 \mathrm{~m}^{2} / \mathrm{g}$ and pore volume of $1.96 \mathrm{~cm}^{3} / \mathrm{g}$. After functionalization, the surface areas and pore volumes are decreased with change of the functional groups because the different sizes of diamines are attached to the pore surfaces and partially block the pores. It corresponds with the decrease of adsorbed $\mathrm{N}_{2}$ amount gradually with the functionalization.

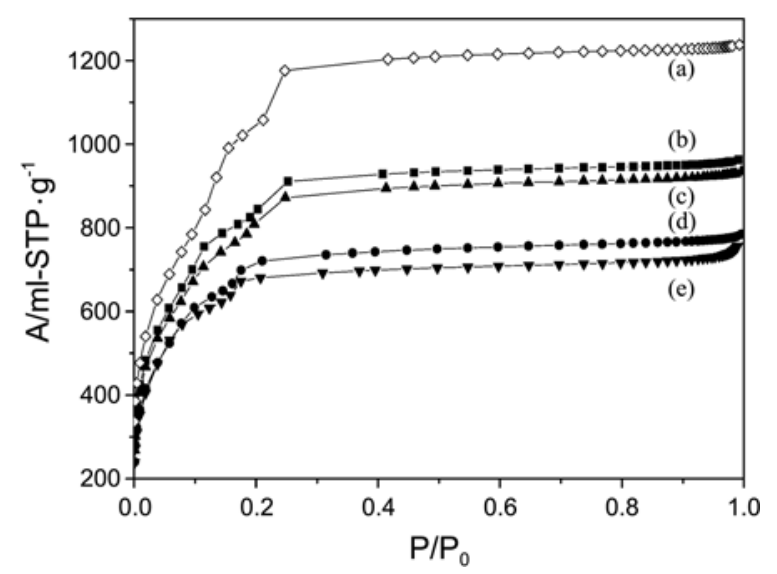

Figure 1. Nitrogen adsorption isotherms of MIL-101 and aminegrafted MIL-101 at $77 \mathrm{~K}$ : (a) purified MIL-101, (b) ED-MIL-101, (c) PD-MIL-101, (d) BD-MIL-101, and (e) DD-MIL-101. 
Table 1. Catalytic activities of amine-grafted MIL-101(Cr) in Knoevenagel condensation of benzaldehyde with ethyl cynoacetate ${ }^{a}$

\begin{tabular}{crccc}
\hline Catalyst & $\mathrm{p} K_{\mathrm{a}}$ & $\begin{array}{c}\text { Conv. } \\
(\%)^{b}\end{array}$ & $\begin{array}{l}\text { Sel. } \\
(\%)^{c}\end{array}$ & $\begin{array}{c}\text { TOF } \\
\left(\mathrm{h}^{-1}\right)^{d}\end{array}$ \\
\hline ED-MIL-101 & 8.66 & 89 & 99 & 3.5 \\
BD-MIL-101 & 10.40 & 98 & 99 & 5.7 \\
DD-MIL-101 & 11.00 & 82 & 99 & 5.6 \\
PD-MIL-101 & 6.08 & 45 & 99 & 1.4 \\
\hline
\end{tabular}

${ }^{a}$ The reaction was carried out at same condition as described in Figure 2. ${ }^{b}$ Conversion of benzaldehyde at $15 \mathrm{~h}$. ${ }^{c}$ Selectivity towards trans-ethyl cyanoacetate. ${ }^{d}$ TOF (turn over frequency): moles of product formed per mole of nitrogen in the grafted MIL-101 per hour (measured at $2 \mathrm{~h}$ ).

However, the shapes of the isotherm curves were not changed after functionalization (Fig. 1). The XRD and BET results revealed that the porous framework of MIL-101 is very stable during the functionalization process. From pore size distribution profiles calculated from adsorption branch of $\mathrm{N}_{2}$-isotherms (Fig. S2), MIL-101 has two-types of mesopores centered in $1.9 / 1.4 \mathrm{~nm}$, respectively. The pore sizes of functionalized samples also decreased, as increased number of hydrocarbons (HC) of grafted amines. As a result, DDMIL-101 has pores of 1.6/1.0 nm, respectively. On the other hand, small molecules functionalized samples as ED-MIL101 are not shown noticeable change in pore size distribution. Additionally, nitrogen contents obtained by elemental analysis (EA) were $2.1 \mathrm{mmol} / \mathrm{g}$ (ED-MIL-101), $1.9 \mathrm{mmol} / \mathrm{g}$ (BD-MIL-101), $1.4 \mathrm{mmol} / \mathrm{g}$ (PD-MIL-101) and $1.3 \mathrm{mmol} / \mathrm{g}$ (DD-MIL-101), respectively. Although the DD-MIL-101 has smallest number of nitrogen contents, it has small pores due to the long chain of DD filled the pores. PD-MIL-101 also has small number of nitrogen content because their weak electronegativity of phenyl amine group acted as to be impediment to amine functionalization at the CUS sites. In addition, this result could be main reason of PD-MIL-101 showing higher surface area than the BD-MIL-101 in spite of longer HC chain.

For the proof of amine-functionalization, the FT-IR spectra (Fig. S3) were measured at $433 \mathrm{~K}$ after the removal of solvent and water contents. The result shows a typical band of -NH (3150-3400 $\left.\mathrm{cm}^{-1}\right)$ and -CH (2800-3000 cm-1$)$ stretching vibration modes as marked in Figure S3. However, the PD-MIL-101 does not possess -CH band and it shows a shift in the $-\mathrm{NH}$ band due to primary amine attached to aromatic ring of PD. (dash-circle) The peak of left-shifted -CH stretching vibrations of BD- and ED-MIL-101 were appeared by neighboring aliphatic - $\mathrm{CH}$ of bonded amine to Lewis acid $\mathrm{Cr}$ sites. These results demonstrated the selective functionalization of diamines into the pores of MIL-101. ${ }^{15}$ The strong intensity of the $-\mathrm{CH}$ stretching band of DD-MIL-101 is appeared by long chain length of DD.

The catalytic activities of the amine functionalized MIL101 in the Knoevenagel condensation of benzaldehyde and ethyl cynoacetate are shown in Figure 2. To confirm the effect of diamine on base catalysis, the reaction was carried out under less reactive condition using toluene as a solvent and lower temperature of $333 \mathrm{~K}$. The samples have high

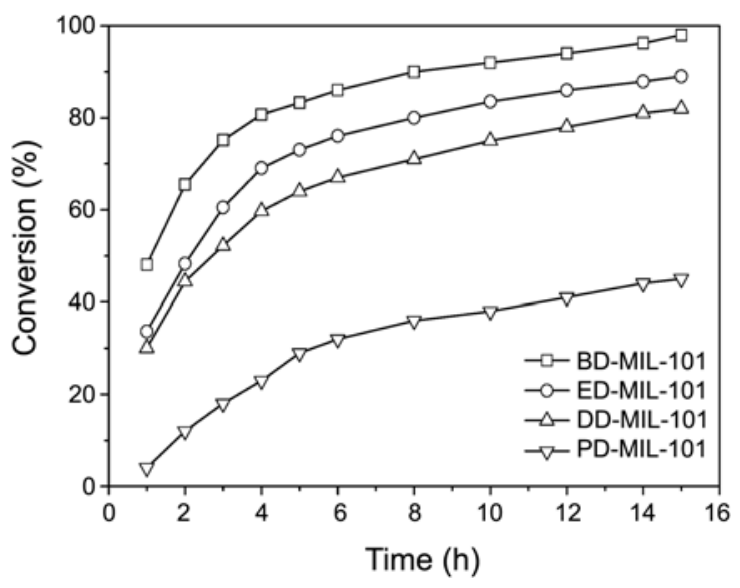

Figure 2. Conversion of benzaldehyde as a function of reaction time over amine-grafted MIL-101 in Knoevenagel condensation. The reaction was carried out with $1 \mathrm{mmol}$ of benzaldehyde, 1 mmol of ethylcynoacetate, $30 \mathrm{mg}$ of catalyst and $25 \mathrm{~mL}$ of toluene heated at $333 \mathrm{~K}$.

selectivity $(>99 \%)$ to trans-ethyl cyanocinnamate at the conversion ranges between 45 to $98 \%$ by different basicities as $\mathrm{p} K_{\mathrm{a}}$ values ${ }^{21}$ of functional group. The condensation reactions were carried out to probe the effect of basicity of the active sites which were created by diamines in the pores of MIL-101. The reactivity of the samples shows correlation with the $\mathrm{p} K_{\mathrm{a}}$ values of the diamines. BD-MIL-101 has the high reactivity as shown in Figure 2 and Table 1 . The reactivity of BD-MIL-101 was both found to be high conversion of $98 \%$ and turn over frequency (TOF) of 5.7. The higher activity attributed to high $\mathrm{p} K_{\mathrm{a}}$ value of the functional group. The reactivity of ED-MIL-101 and PD-MIL-101 with lower $\mathrm{p} K_{\mathrm{a}}$ values is lower than BD- and DD- functionalized samples. Although ED-MIL-101 still has large pore size and high surface area, it shows low conversion activity of $89 \%$ and TOF value of 3.5 because ED- is not high $\mathrm{p} K_{\mathrm{a}}$ value. The PD-MIL-101 has lower $\mathrm{p} K_{\mathrm{a}}$ value of 6.08 due to the delocalization of lone pair of electrons on nitrogen. Hence, the PD-MIL-101 has the lowest basicity and the lowest catalytic activity as conversion activity of $44.8 \%$ and TOF valve of 1.4. However, DD-MIL-101 with higher $\mathrm{p} K_{\mathrm{a}}$ of 11.00 shows lower conversion activity of $82 \%$. The lower reactivity of DD-MIL-101 attributed to the less number of basic sites for the reaction as well as the longest chain length of hindered diffusion of the reactant molecules. Moreover, the amine of the long carbon chain might be has hydrogen bond with adjacent amines or the free amine group can graft with the neighboring CUS sites. ${ }^{22}$

In conclusion, we have demonstrated that amines with different basicities successfully functionalized into the pores of MIL-101 and amine functionalized chromium terephthalate used as a base catalyst. The catalytic activity of amine functionalized MIL-101 in Knoevenagel condensation of ethylcyanoacetate and benzaldehyde depends on their basicities. The reactivity of these catalytic materials could be also affected by their pore size and/or surface area, which governs the facile diffusion of the molecules through the 
channels of the MIL-101. The present strategy ensures the development of new functionalities and lead to MOF applications of practically useful heterogeneous base catalysts for chemical transformations.

\section{Experimental Section}

The MIL-101 was synthesized by a hydrothermal reaction of terephthalic acid with $\mathrm{Cr}\left(\mathrm{NO}_{3}\right)_{3} \cdot 9 \mathrm{H}_{2} \mathrm{O}, \mathrm{HF}$, and $\mathrm{H}_{2} \mathrm{O}$ at $493 \mathrm{~K}$ in $8 \mathrm{~h}$ according to the procedure proposed by our previous report. ${ }^{7,9}$ The as-synthesized MIL-101 was further purified by a three-step process using double filtration, hot ethanol, and aqueous $\mathrm{NH}_{4} \mathrm{~F}$ solutions. The purified MIL-101 $(0.5 \mathrm{~g})$ was dehydrated at $423 \mathrm{~K}$ for $12 \mathrm{~h}$ and then suspended in anhydrous toluene $(30 \mathrm{~mL}) .1 .5 \mathrm{mmol}$ of $\mathrm{ED}, \mathrm{BD}, \mathrm{DD}$ and PD were added individually and the mixture was stirred under reflux for $12 \mathrm{~h}$ in nitrogen environment. The functionalized MIL-101s or samples? were tested for their catalytic activities in the Knovenagel condensation reaction. The reaction was carried out with $1 \mathrm{mmol}$ of benzaldehyde, 1 mmol of ethylcynoacetate, $30 \mathrm{mg}$ of catalyst and $25 \mathrm{~mL}$ of toluene heated at $333 \mathrm{~K}$.

Acknowledgments. This research was supported by the Pioneer Research Center Program through the National Research Foundation of Korea funded by the Ministry of Education, Science and Technology (2011-0001667/20110001669) and the Korea Research Foundation Grant funded by the Korean Government (357-2008-1-C00070). The authors thank Prof. Gerard Ferey, and Dr. Christian Serre for their helpful discussion.

\section{References}

1. Yaghi, O. M.; O’keeffe, M.; Ockwig, N. W.; Chae, H. K.; Eddaoudi, M.; Kim, J. Nature 2003, 423, 705.

2. Rosi, N. L.; Eckert, J.; Eddaoudi, M.; Vodak, D. T.; Kim, J.; O'Keeffe, M.; Yaghi, O. M. Science 2003, 300, 1127.

3. Rosseinsky, M. J. Nat. Mat. 2010, 9, 609.

4. Latroche, M.; Surble, S.; Serre, C.; Draznieks, C. M.; Lewellyn, P. L.; Lee, J. H.; Chang, J.-S.; Jhung, S. H.; Férey, G. Angew. Chem.
Int. Ed. 2006, 45, 8227.

5. Hamon, L.; Serre, C.; Devic, T.; Loiseau, T.; Millange, F.; Férey, G.; Weireld, G. D. J. Am. Chem. Soc. 2009, 131, 8775.

6. Férey, G.; Mellot-Draznieks, C.; Serre, C.; Millange, F.; Dutour, J.; Surblé, S.; Margiolaki, I. Science 2005, 309, 2040.

7. Hwang, Y. K.; Hong, D. Y.; Chang, J.-S.; Jhung, S. H.; Seo, Y. K.; Kim, J. H.; Vimont, A.; Daturi, M.; Serre, C.; Férey, G. Angew. Chem. Int. Ed. 2008, 47, 4144

8. Horcajada, P.; Chalati, T.; Serre, C.; Gillet, B.; Sebrie, C.; Baati, T.; Eubank, J. F.; Heurtaux, D.; Clayette, P.; Kreuz, C.; Chang, J. S.; Hwang, Y. K.; Marsaud, V.; Bories, P. N.; Cynober, L.; Gil, S.; Férey, G.; Couvreur, P.; Gref, R. Nat. Mater. 2010, 9, 172.

9. Hong, D.-Y.; Hwang, Y. K.; Serre, C.; Férey, G.; Chang, J. S. Adv. Funt. Mater. 2009, 19, 1537.

10. Devic, T.; Horcajada, P.; Serre, C.; Salles, F.; Maurin, G.; Moulin, B.; Heurtaux, D.; Clet, G.; Vimont, A.; Greneche, J. M.; Ouay, B. L.; Moreau, F.; Magnier, E.; Filinchuk, Y.; Marrot, J.; Lavalley, J. C.; Daturi, M.; Férey, G. J. Am. Chem. Soc. 2010, 132, 1127.

11. Kitaura, R.; Seki, K.; Akiyama, G.; Kitagawa, S. Angew. Chem. Int. Ed. 2003, 42, 428.

12. Tanabe, K. K.; Wang, Z.; Cohen, S. M. J. Am. Chem. Soc. 2008, 130,8508 .

13. Hasegawa, S.; Horike, S.; Matsuda, R.; Furukawa, S.; Mochizuki, K.; Kinoshita, Y.; Kitagawa, S. J. Am. Chem. Soc. 2007, 129, 2607.

14. Gascon, J.; Aktay, U.; Hernandez-Alonso, M. D.; van Klink, G. P. M.; Kapteijn, F. J. Catal. 2009, 261, 75.

15. Tanabe, K. K.; Cohen, S. M. Angew. Chem. Int. Ed. 2009, 48, 7424.

16. Seo, J. S.; Whang, D.; Lee, H.; Jun, S. I.; Oh, J.; Jeon, Y. J.; Kim, K. Nature 2000, 404, 982.

17. Xamena, F. X. L.; Casanova, O.; Tailleur, R. G.; Garcia, H.; Corma, A. J. Catal. 2008, 255, 220.

18. Xamena, F. X. L.; Abad, A.; Corma, A.; Garcia, H. J. Catal. 2007, 250, 294.

19. Hwang, Y. K.; Hong, D.-Y.; Chang, J.-S.; Seo, H.; Kim, J.; Jhung, S. H.; Serre, C.; Ferey, G. Appl. Catal. A. Gen. 2009, 358, 249.

20. (a) Krishnan, K.; Plane, R. A. Inorg. Chem. 1966, 5, 852. (b) Young, D. A.; Freedman, T. B.; Lipp, E. D.; Nafie, L. A. J. Am. Chem. Soc. 1986, 108, 7255.

21. (a) Dean, J. A. In Lange's Handbook of Chemistry, $14^{\text {th }}$ ed.; Smith, S. M., Ed.; McGraw-Hill: New York, 1992; Chap. 8, p 1971. (b) Bryantsev, V. S.; Diallo, M. S.; Goddard, W. A. J. Phys. Chem. A 2007, 111, 4422. (c) Gross, K. C.; Seybold, P. G. Inter. J. Quant. Chem. 2000, 80, 1107. (d) Eian, G. L. U.S patent., 3935012, 1976.

22. McKittrick, M. W.; Jones, C. W. Chem. Mater. 2003, 15, 1132. 


\title{
Effect of Diamine in Amine-Functionalized MIL-101 for Knoevenagel Condensation
}

\author{
Palraj Kasinathan, ${ }^{\dagger, *}$ You-Kyong Seo, ${ }^{\dagger}$ Kyu-Eun Shim, ${ }^{\dagger \neq}$ Young Kyu Hwang, ${ }^{\dagger, \star, *}$ U-Hwang Lee, ${ }^{\dagger, *}$ Dong Won Hwang, ${ }^{\dagger}$ \\ Do-Young Hong, ${ }^{\dagger}$ Shiva B. Halligudi, ${ }^{\dagger}$ and Jong-San Chang ${ }^{\dagger, \star}$
}
${ }^{\dagger}$ Research Group for Nanocatalyst, Korea Research Institute of Chemical Technology, Daejeon 305-600, Korea E-mail: ykhwang@krict.re.kr

:School of Science, University of Science and Technology (UST), Daejeon, 305-333, Korea Received February 28, 2011, Accepted April 6, 2011

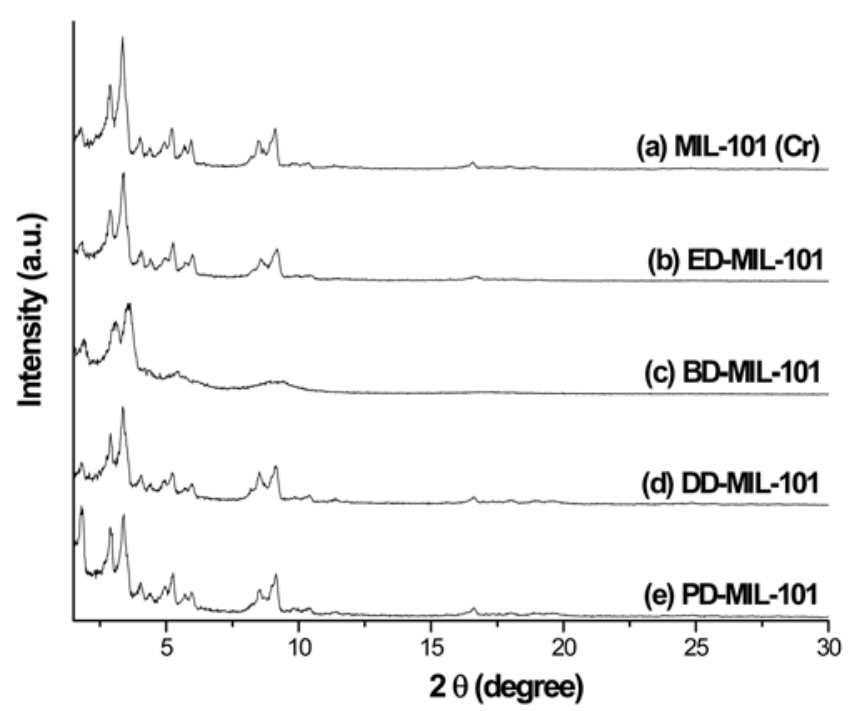

Figure S1. XRD patterns of (a) as-prepared Porous chromium terephthalate (MIL-101(Cr)) and (b-e) amines functionalized samples; (b) ethane-1,2-diamine (ED-MIL-101) (c) butane-1,4diamine (BD-MIL-101) (d) decane-1,10-diamine (DD-MIL-101) and (e) benzene-1,4-diamine (PD-MIL-101), respectively.

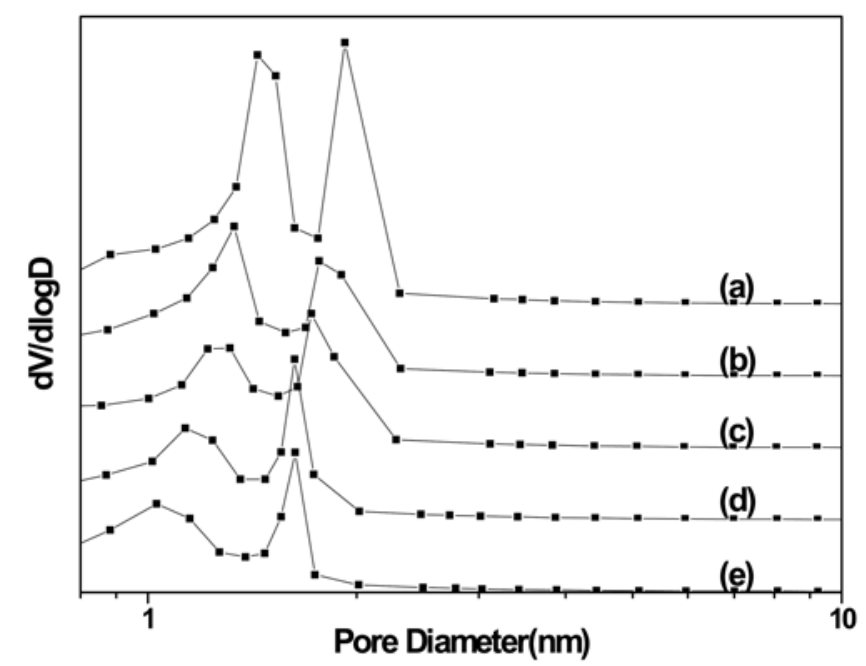

Figure S2. Pore-size distribution curves with adsorption volume and pore diameter. (a) as-prepared MIL-101, (b) ED-MIL-101, (c) PD-MIL-101, (d) BD-MIL-101 and (e) DD-MIL-101, respectively.

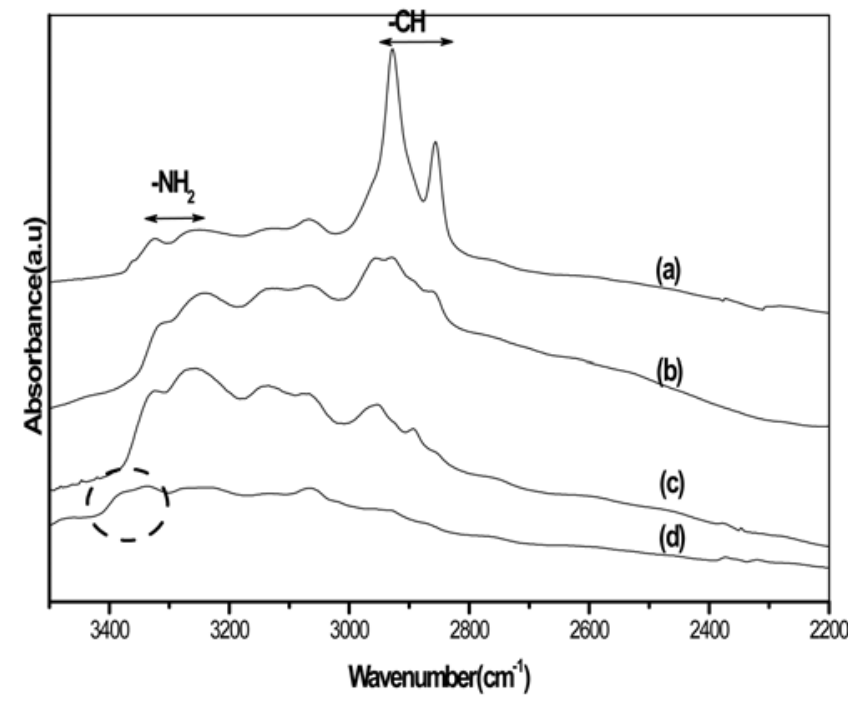

Figure S3. FT-IR Spectra of amine functionalized MIL-101 samples at 473 K. (a) DD-MIL-101, (c) BD-MIL-101, (d) EDMIL-101 and (e) PD-MIL-101.

Table S1. Physicochemical properties of as-prepared and functionalized MIL-101 samples

\begin{tabular}{ccccc}
\hline Sample $^{a}$ & $\begin{array}{c}\mathrm{N} \text { content } \\
\left(\mathrm{mmolg}^{-1}\right)^{b}\end{array}$ & $\begin{array}{c}\mathrm{S}_{\mathrm{BET}} \\
\left(\mathrm{m}^{2} \mathrm{~g}^{-1}\right)^{c}\end{array}$ & $\begin{array}{c}\mathrm{P} . \mathrm{V} \\
\left(\mathrm{cm}^{3} \mathrm{~g}^{-1}\right)^{d}\end{array}$ & $\begin{array}{c}\text { PSD } \\
(\mathrm{nm})^{e}\end{array}$ \\
\hline MIL-101(Cr) & - & 4035 & 1.96 & $1.9 / 1.4$ \\
ED-MIL-101 & 2.1 & 3101 & 1.49 & $1.8 / 1.3$ \\
PD-MIL-101 & 1.4 & 2981 & 1.44 & $1.7 / 1.2$ \\
BD-MIL-101 & 1.9 & 2603 & 1.21 & $1.6 / 1.1$ \\
DD-MIL-101 & 1.3 & 2446 & 1.17 & $1.6 / 1.0$ \\
\hline
\end{tabular}

${ }^{a} \mathrm{ED}, \mathrm{BD}, \mathrm{DD}$ and $\mathrm{PD}$ are abbreviation of ethane-1,2-diamine, butane1,4-diamine, decane-1,10-diamine and benzene-1,4-diamine, respectively. ${ }^{b}$ Determined from Elemental analysis. ${ }^{c}$ Surface area evaluated using the Brunauer-Emmett-Teller (BET) method from the $\mathrm{N}_{2}$ adsorption isotherm. ${ }^{d}$ Pore volume taken by a single point method at $\mathrm{p} / \mathrm{p}^{0}=0.99$. ${ }^{e}$ Pore size distribution values are obtained by the BJH equation. 